\title{
Flagellate dermatitis after consumption of Shiitake mushrooms
}

\author{
Agnieszka B. Czarnecka, Burkhard Kreft, Wolfgang Ch. Marsch
}

Universitätsklink für Dermatologie und Venerologie, Martin-Luther Universität Halle-Wittenberg, Halle, Germany Head of Clinic: Prof. Wolfgang C. Marsch MD, PhD

Postep Derm Alergol 2014; XXXI, 3: 187-190

DOI: 10.5114/pdia.2014.40929

\begin{abstract}
Flagellate dermatitis occurs in patients who have eaten Shiitake mushrooms. We are reporting on a 55-year-old man, who developed whiplash-striped, severely itching efflorescences on the trunk 3 days after eating Lentinula edodes. Flagellate dermatitis is also known as a cutaneous side effect of bleomycin therapy.
\end{abstract}

Key words: Shiitake mushrooms, toxicoderma, flagellate dermatitis, latency, whiplash-like efflorescences.

\section{Introduction}

Shiitake mushrooms (Lentinus edodes) (Figure 1), a woodland type of mushrooms used in Japanese/ Chinese cuisine, are the second-most common edible mushrooms in the world. The precise number of tons consumed per year is not known but is estimated in the 10,000-ton range worldwide [1]. In addition to its culinary properties (Umami), an antihypertensive effect, reduction of elevated cholesterol levels and an anticarcinogenic property are known. For this reason, the Shiitake mushroom plays a large role in traditional Asian medicine.

A severely-itching dermatitis (toxicoderma) following consumption of the mushroom was first reported by $\mathrm{Na}$ kamura in 1977 [2]. Typically, 24-48 h after eating raw or half-cooked Shiitake mushrooms, the patient developed severely-itching, isolated or grouped papules or papulovesicles with striped, infiltrated erythemas, which arose in a Köbner phenomenon due to stripe-like scratching [3].

The preferred localizations of the dermatosis are the trunk, extremities and the nape area, less often the face or hair-covered scalp [2]. No life-threatening systemic reactions have been documented thus far. The usually spontaneous regression of skin symptoms lasts from a few days to several weeks.

\section{Case report}

A 55-year-old German patient came to our clinic with pruriginous stripes of whiplash-like efflorescences on the trunk, with acute onset and lasting several hours.
One day before the skin changes occurred, the patient had been working in the atomic energy plant Isar in Essenbach/Lower Bavaria, and his back had come into contact with questionable radioactive tarpaulins used to cover the cooling basins. Radioactivity measurements in the atomic energy plant were normal.

When direct questions were repeated, the patient reported that he had eaten at an Asian restaurant 3 days earlier and had consumed mushrooms. The patient could not identify the mushrooms, and we were unable to obtain precise information from the restaurant, except that mushroom dishes often include Shiitake mushrooms.

The patient is known to suffer from diabetes mellitus type 2 requiring tablet therapy and arterial hypertension. He denied taking new medications or phytotherapeutics.

Examination revealed severely-itching parallel, striped whiplash-like infiltrated erythemas with severe itching on the trunk and upper extremities. In addition, there were papulovesicles on urticarial erythemas on the shoulders (Figures 2-4).

The patient in good general and nutritional condition, neurologically inconspicuous. Medications: Metformin, Glimepiride, Enalapril.

Laboratory: glucose $10.4 \mathrm{mmol} / \mathrm{l}$, urea $5.2 \mathrm{mmol} / \mathrm{l}$, alanine transaminase (ALT) 0.8 umol/l, mean corpuscular volume (MCV) $83 \mathrm{fl}$. The other routine laboratory parameters, including electrolytes, retention parameters, aspartate transaminase (AST), thyroid-stimulating hormone (TSH), C-reactive protein (CRP), complete blood count, were in the normal range.

Address for correspondence: Agnieszka B. Czarnecka MD, PhD, Universitätsklink für Dermatologie und Venerologie, Martin-Luther Universität Halle-Wittenberg, Ernst-Grube-Str. 40, 06120 Halle, Germany, phone: +49 15111514115, e-mail: agni.czarnecka@gmail.com Received: 28.08.2013, accepted: 10.09.2013. 


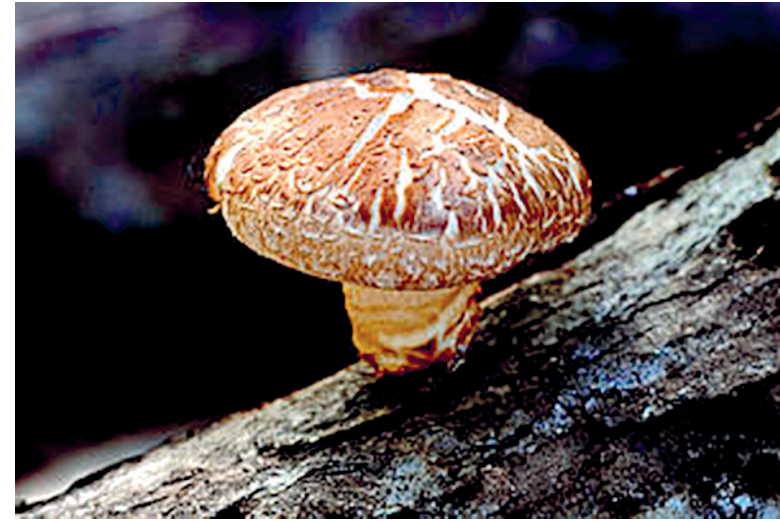

Figure 1. Shiitake mushroom

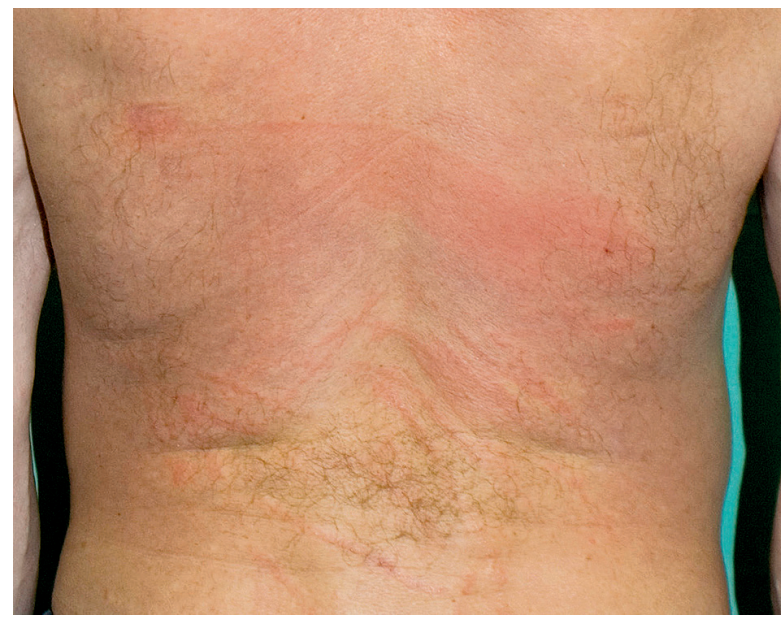

Figure 3. Close-up view of parallel, striped whiplash-like infiltrated erythemas on the trunk

Two skin biopsies taken from the right shoulder and the back. The histology showed the following, unspecific characteristics (Figures $5 \mathrm{~A}$ and $5 \mathrm{~B}$ ): severe edema of the Stratum papillare, mild focal (not spreading) acute lymphocytic eczema reaction, superficial, cuff-shaped perivascular lymphocytic infiltrate.

Based on the unmistakable clinical pattern with stripes of whiplash-like, severely-itching efflorescences and the anamnesis (onset of the efflorescences with a latency of ca. $72 \mathrm{~h}$ after eating mushrooms in an Asian restaurant) and detailed histological diagnostic tests, we diagnosed flagellate dermatitis following consumption of Shiitake mushrooms.

We treated the patient systemically with Prednisolone $80 \mathrm{mg} /$ day per os for 2 days. In addition, we prescribed Fexofenadine $180 \mathrm{mg} 2 \times$ day to suppress the itching. Local therapy consisted of Mometasone $0.1 \%$ in cold cream cum $30 \%$ aqua $2 \times$ daily. This led to regression of the skin changes within a few days.

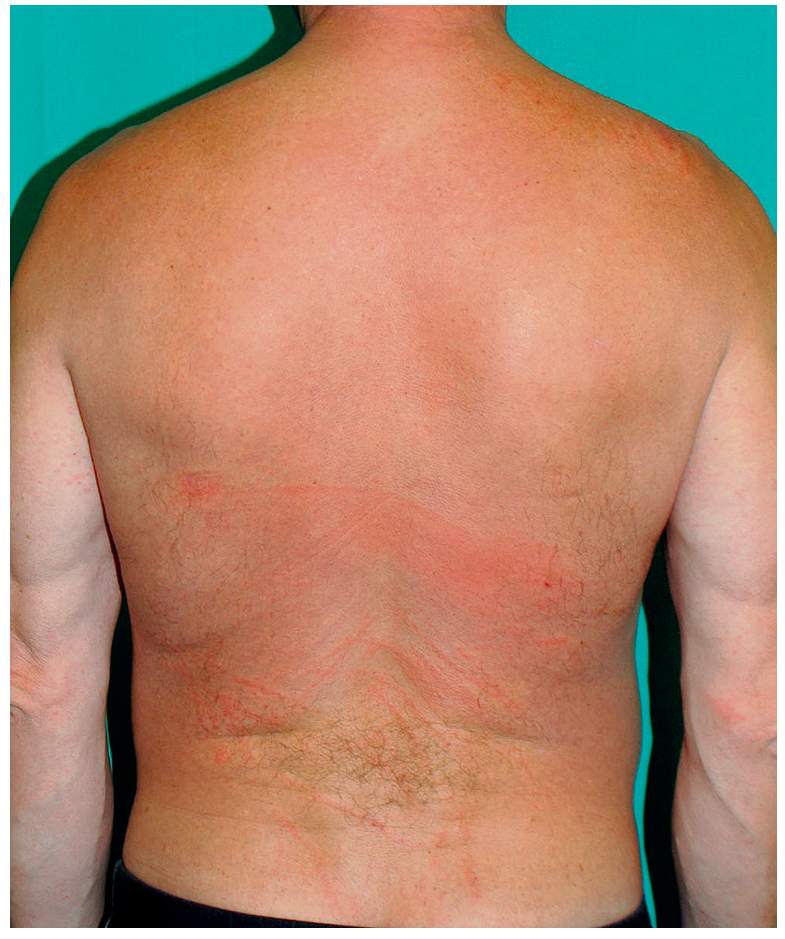

Figure 2. Parallel, striped whiplash-like infiltrated erythemas with severe itching on the trunk

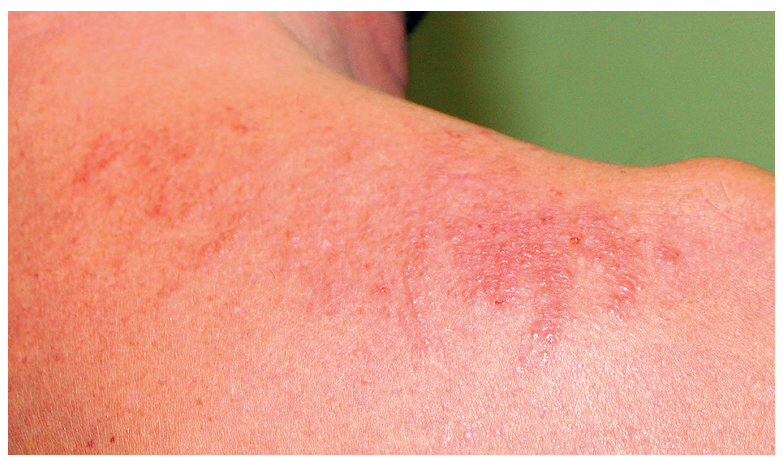

Figure 4. Papulovesicles on urticarial erythemas on the right shoulder

\section{Discussion}

Flagellate dermatitis (Toxicoderma) [2] is a rare, presumedly toxic epidermal damage following consumption of raw or half-cooked Shiitake mushrooms [2, 4]. Characteristically the patients develop parallel, whiplash-like infiltrated erythemas with papulae or papulovesicles, arranged like scratches and associated with severe itching 1-2 days after eating Shiitake mushrooms. The localizations are preferentially the trunk, the extremities and the nape of the neck $[2,5]$. The clinical pattern gives rise to the name flagellate dermatitis, since the skin changes appear like skin damage caused by whiplashes [3, 4]. The 


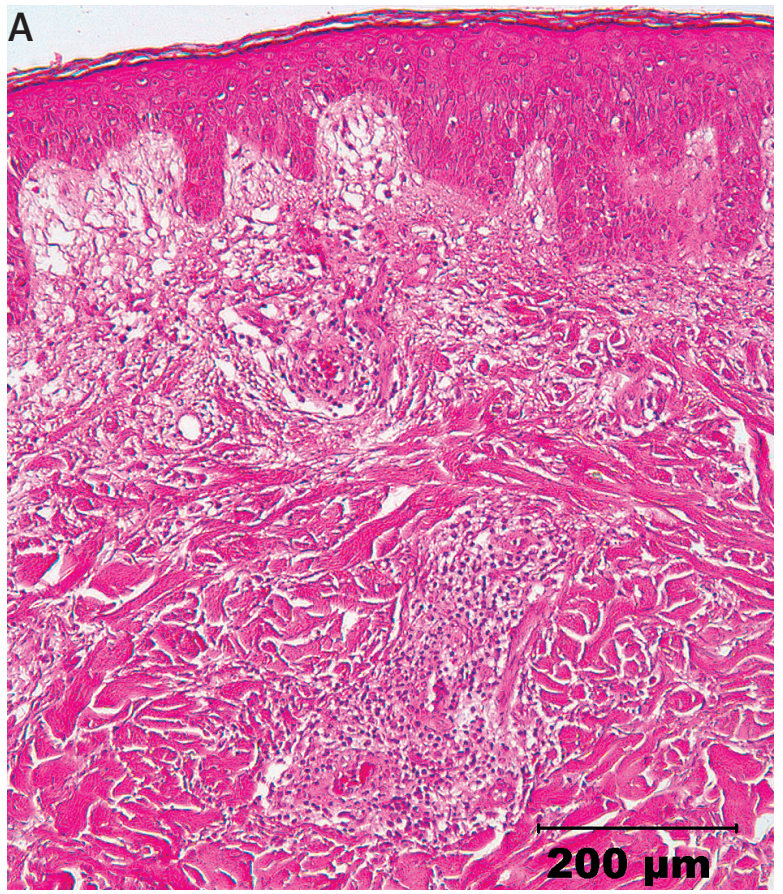

Flagellants (Lat. flagellum $=$ whip) were a lay Christian movement in the Middle Ages. The religious practices of the Flagellants included public self-flagellation as penance and purification from sin.

In Shiitake dermatitis, the thermolabile polysaccharide lentinan, one of the substances in the mushroom, is held responsible for the onset of the distinctive skin efflorescences $[3,6]$. Chemically speaking, lentinan is a polysaccharide and supposedly has an immunomodulating and antiproliferative effect, for which reason it has been administered in Japan since 2000 as an adjuvant cancer therapy [7]. Moreover, lentinan induces the production of the inflammation-promoting signal substance IL-1 and has a vasodilatative effect [8-10]. However, the precise pathogenesis of Shiitake dermatitis is not yet completely understood. In general, the hypothesis of a toxic reaction is preferred, but there is increasing evidence that a genuine immunological sensitization in the sense of a T-cell-mediated late reaction could be involved [11]. It is known that an allergic reaction in the sense of bronchial asthma, contact dermatitis or allergic alveolitis may occur after contact with Shiitake mushrooms, but prickto-prick or scratch testing is often negative in Shiitake dermatitis. Whether cofactors, such as medications like ACE-inhibitors or diuretics, or UV-exposure, possibly play an additional role is also under discussion $[4,10]$.

Recent reports show that nearly half of the patients have developed flagellate dermatitis after eating thoroughly-cooked Shiitake mushrooms [4].

Repeated consumption of Shiitake can elicit a typical recurrence, so Shiitake should be avoided [10]. The histological characteristics of Shiitake dermatitis are

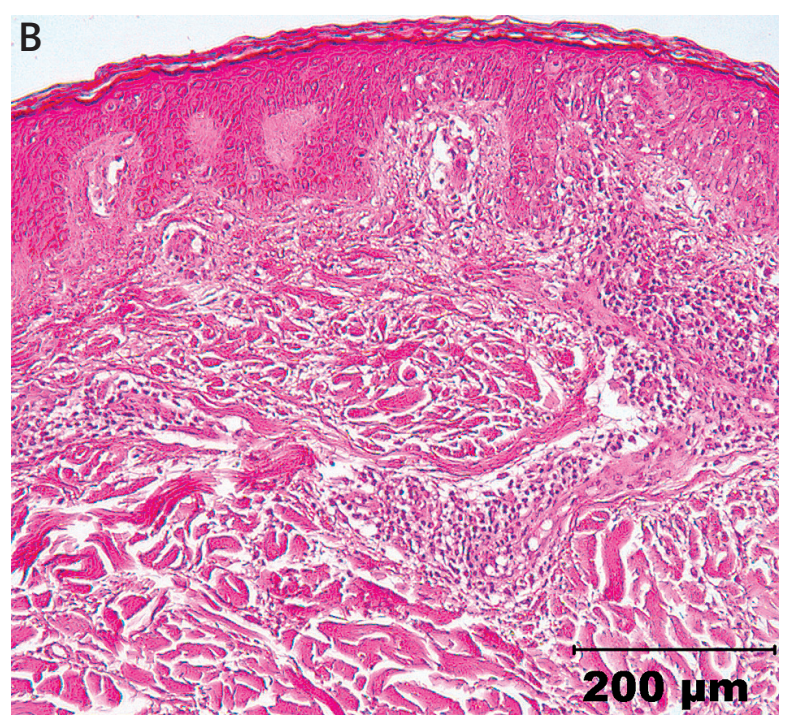

Figure 5 A-B. Histopathology (skin punch biopsy): severe edema of the Stratum papillare, mild focal (not spreading) acute lymphocytic eczema reaction, superficial, cuff-shaped perivascular lymphocytic infiltrate

unspecific, like the bleomycin-induced variant; there is epidermal spongiosis, as in an acute eczema disorder, and a perivascular, cuff-shaped lymphocytic infiltrate in the dermis [3, 5].

In differential diagnosis, flagellate dermatitis should be considered after therapy with bleomycin (fungus extract from Streptomyces verticillus) and its derivatives, whereby clear differences are known in the clinical presentation and pathogenesis. Typically, there is a postinflammatory hyperpigmentation $[12,13]$ and mucosal involvement is also possible. The histology is variable and not particularly specific [14], and the same applies to Shiitake dermatitis.

Bleomycin is a cytostatic antibiotic belonging to the glycopeptides group and is enzymatically inactivated by hydrolase. The enzyme (BLM) is found in the skin and considerably less in the lung, so that an increased cutaneous concentration of the medication leads to a toxic, dose-dependent stimulation of melanocytes and possibly to irritation of afferent nerve fibers with consecutive itching and hyperpigmentation as a result of scratching [12]. This pattern has not been described for any other chemotherapeutic to date. But a case report from the USA recently described flagellate dermatitis after bendamustine therapy in one patient with chronic lymphatic leukemia (CLL) [15].

In addition, flagellate dermatitis has also been reported in dermatomyositis and Morbus Still/adult-onset Still's disease (Table 1) [16].

In Europe, as yet, only a few cases of flagellate dermatitis have been reported after consumption of Shiitake mushrooms, but with the increasing popularity of Asian 
Table 1. Causes of flagellate dermatitis

\begin{tabular}{lcc}
\hline Foods & Medicaments & Autoimmune diseases \\
\hline Shiitake & Bleomycin & Dermatomyositis \\
\hline & Bendamustine & $\begin{array}{c}\text { Morbus still/adult-onset } \\
\text { Still's disease }\end{array}$ \\
\hline
\end{tabular}

cuisine in our geographic area, cases of flagellate dermatitis after consumption of Shiitake mushrooms will undoubtedly occur more often, so that we dermatologists must be aware of this disease.

\section{Conflict of interest}

None declared.

\section{References}

1. Gesundheitliches Risiko von Shiitake-Pilzen. Stellungnahme des Bundesinstitut für Risikobewertung vom 23.06.2004.

2. Nakamura T. Shiitake (Lentinus edodes) dermatitis. Contact Derm 1992; 27: 65-70.

3. Haas N, Vogt R, Sterry W. Shiitake-dermatitis. Hautarzt 2001; 52: 132-5.

4. Maier T, Herzinger T. Flagellanten dermatitis auf Shiitake-Pilze. Hautarzt 2007; 58: 1021-2.

5. Wagner G, Sachse MM. Parallel angeordnete streifenförmige Erytheme am Nacken, an den Schultern und am vorderen Dekollete. J Dtsch Dermatol Ges 2011; 9: 555-7.

6. Lippert U, Martin V, Schwertfeger C, et al. Shiitake dermatitis. Br J Dermatol 2003; 148: 178-9.

7. Wikipedia; Ajinomoto: History of Pharmaceuticals Business, October 2008

8. Hanada K, Hashimoto I. Flagellate mushroom (Shiitake) dermatitis and photosensitivity. Dermatology 1998; 197: 255-7.

9. Diaz-Corpas T, Mateu-Puchades A, Coll-Puigserver MN, Marquina-Vila A. Flagellate dermatitis after eating shiitake mushrooms. Acta Dermosifiliogr 2011; 102: 830-2.

10. Poppe LM, Anders D, Kneitz H, et al. Flagellate dermatitis caused by shiitake mushrooms. An Bras Dermatol 2012; 87: 463-6.

11. Aalto-Korte K, Susitaival P, Kaminska R, Mäkinen-Kiljunen S. Occupational protein contact dermatitis from shiitake mushroom and demonstration of shiitake-specific immunoglobulin E. Contact Derm 2005, 53: 211-3.

12. Albig J, Gollnick H, Detmar M, Orfanos CE. Flagellatartige Hyperpigmentierung durch Bleomycin. Hautarzt 1992; 43: 376-9.

13. Simpson RC, Da Forno P, Nagarajan C, Harman KE. A pruritic rash in a patient with Hodgkin lymphoma. Bleomycin-induced flagellate dermatosis. Clin Exp Dermatol 2011; 36: 680-2.

14. Ziemer M, Goetze S, Juhasz K, Elsner P. Flagellate dermatitis as a bleomycin-specific adverse effect of cytostatic therapy. Am J Clin Dermatol 2011; 12: 68-76.

15. Mahmoud BH, Eide MJ. Bendamustine-induced, flagellate dermatitis'. Dermatol Online J 2012; 18: 12.

16. Yamamoto T, Nishioka K. Flagellate erythema. Int I Dermatol 2006; 45: 627-31. 